\title{
TREINAMENTO DE FORÇA, COMO INSTRUMENTO PARA REVERTER OU AMENIZAR OS INDIVÍDUOS ACOMETIDOS POR DESVIOS POSTURAIS
}

\section{ARTIGO ORIGINAL}

SANTOS, William da Costa ${ }^{1}$

MOREIRA, Elisângela Claudia de Medeiros ${ }^{2}$

DIAS, Cláudio Gellis de Mattos ${ }^{3}$

FECURY, Amanda Alves ${ }^{4}$

NETO, Manoel Samuel da Cruz ${ }^{5}$

DENDASCK, Carla Viana ${ }^{6}$

${ }^{1}$ Graduado em Educação Física. Docente da rede de Ensino do Estado do Pará.

${ }^{2}$ Mestre em Teoria e Pesquisa do Comportamento. Docente da Universidade do Estado do Pará - UEPA. Doutoranda em Doenças Tropicais na Universidade Federal do Pará - NMT/UFPA.

${ }^{3}$ Doutor em Teoria e Pesquisa do Comportamento. Docente e Pesquisador do Instituto Federal do Amapá - IFAP.

${ }^{4}$ Doutora em Doenças Tropicais. Docente e Pesquisadora da Universidade Federal do Amapá -UNIFAP. Pesquisadora colaboradora do Núcleo de Medicina Tropical da UFPA (NMT-UFPA).

${ }^{5}$ Mestre em Enfermagem. Docente e Pesquisador na Faculdade Brasil Amazônia FIBRA.

${ }^{6}$ Teóloga. Doutora em Psicanálise Clínica. Pesquisadora do Centro de Pesquisa e Estudos Avançados, São Paulo, SP. 
GOMES, Cícero Augusto Chaves ${ }^{7}$

SILVA, Matheus Tavares ${ }^{8}$

MOREIRA, Rodrigo Canto ${ }^{9}$

OLIVEIRA, Euzébio de ${ }^{10}$

SANTOS, William da Costa. Et al. Treinamento de força, como instrumento para reverter ou amenizar os indivíduos acometidos por desvios posturais. Revista Científica Multidisciplinar Núcleo do Conhecimento. Ano 04, Ed. 12, Vol. 07, pp. 4360. Dezembro de 2019. ISSN: 2448-0959, Link de acesso: https://www.nucleodoconhecimento.com.br/saude/desvios-posturais

\section{RESUMO}

O desvio postural refere-se ao encurtamento muscular, caracterizado como: escoliose, hipercifóse torácica e hiperlordose lombar. O presente estudo é de cunho quantitativo, teve como objetivo verificar se o treinamento de força pode amenizar ou reconduzir a coluna na sua posição anatômica e objetivo específico analisar os ângulos entre os pontos anatômicos. Participaram deste estudo 7 indivíduos, sendo 2 homens e uma mulher como escoliose, 1 homem e 2 mulheres com hipercífose e 1 mulher com hiperlordose. A idade média dos indivíduos foi de 23,5 anos (DP \pm ano). Foi utilizada a avaliação postural por simetrografia através do instrumento

${ }^{7}$ Graduado em Educação Física. Docente da rede Municipal de Ensino do Estado do Pará.

${ }^{8}$ Graduado em Educação Física. Docente da rede de Ensino do Estado do Pará.

${ }^{9}$ Mestre em Neurociência e Comportamento pela Universidade Federal do Pará. Docente e Pesquisador da Universidade do Estado do Pará - UEPA.

10 Doutor em Medicina/Doenças Tropicais. Docente e Pesquisador na Universidade Federal do Pará - UFPA. Pesquisador Colaborador do Núcleo de Medicina Tropical NMT/UFPA, Belém (PA), Brasil. 
Simetrógrafo, o software Sapo - versão 0.69. Para análise estatística dos dados foram utilizados o programa SPSS (Statistical Pakage for Science Social), versão 22.0 para Mac, o sapo e o Test $T$ pareado. O nível de significância adotado foi $p \leq 0,05$. Os resultados apontaram melhoras significativas no alinhamento horizontal dos acrômios, na VA e também no alinhamento horizontal da cabeça (acrômio) na VLD, quando utilizado o Test T pareado. Quando os indivíduos foram analisados individualmente, percebemos melhora significativa em vários ângulos anatômicos, em todos os avaliados, todavia, destacamos dois indivíduos escolióticos, um do sexo masculino e o outro do feminino, com melhoras em 8 e 9 ângulos analisados, respectivamente.

Palavras-chave: Desvios posturais, coluna Vertebral, treinamento de força.

\section{INTRODUÇÃO}

A postura do ser humano passou por uma série de transformações, iniciadas a milhares de anos, saindo da posição quadrúpede para uma postura ereta, adotada no momento em que os membros superiores deixaram de ser utilizados para a locomoção e serem usados na busca de alimentos (BLACK, 1993), adaptando-se a sua nova posição, corroborando com a teoria de Darwin.

Incorporados à espécie e à coluna vertebral, essas alterações anatômicas, só foi possível devido sofrerem mudanças em suas estruturas ósseas, musculares e na coluna vertebral, com o surgimento das curvas lordóticas na região cervical e lombar, sendo quatro curvaturas fisiológicas: cervical, torácica, lombar e coccígea (RESENDE; SANCHES, 1992). Pois a posição bípede só foi possível devido à coluna e os músculos, passando a ter curvas $(\mathrm{KNOPLICH}, 2016)$. Curvaturas que tem por finalidade distribuir as forças que agem sobre o corpo humano (BLACK, 1993). Pois, a alteração da coluna já agrupada a posição bípede, é outra vez modificada por vários fatores: como a má postura adotada, devido à idade, tipos de trabalho e outros.

A coluna vertebral tem sido tema de estudo ao longo dos anos, por ser a principal locomoção central do ser humano. Segundo Kapandji (2008) a coluna vertebral é o eixo do corpo na qual deve conciliar dois imperativos mecânicos contraditórios: a 
solidez (rigidez) e flexibilidade que consegue essa proeza devido a sua estrutura que é formada por um conjunto de ossos de pequenas dimensões, empilhados e com mobilidades entre si.

Em decorrência da má postura adotada pelos indivíduos, a coluna vertebral, apesar de ser rígida, porém flexível, pode desencadear algumas alterações nas curvas lordóticas e cifóticas, caracterizando as fisiopatologias: escoliose, hiperlordose lombar e cervical, hipercifose torácica. Escoliose é uma disfunção caracterizada com o desvio lateral da coluna, na qual pode ser classificada segundo sua etiologia em estrutural e não-estrutural (HEBERT et al., 2009).

Hiperlordose é um desequilíbrio dos músculos. Hiperlordose lombar é caracterizada pelo aumento da curvatura lombar (VERDERI, 2008). A hiperlordose cervical associase a anteriorização da cabeça à frente do centro de gravidade, alterando a disposição da musculatura responsável pelo movimento dos maxilares e pescoço (HAMILL; KNUTZEN, 1999).

Hipercifóse torácica também conhecida como doença de Scheuermann é uma deformidade da coluna, ou seja, é o aumento da cifose torácica que acomete ambos os sexos e de origem desconhecida (HEBERT et al., 2009).

Devido esses desvios, que muitos humanos são acometidos, Zatsiorsk e kraemer (2008) recomendam, TF para recuperação postural ou para amenizar os efeitos fisiopatológicos desses desvios na coluna vertebral. O TF pode ser classificado de várias formas: estático (isométricos) e dinâmico (concêntrico, excêntrico, reversível e isocinético). O TF é um método que pode ser aplicado em todas as faixas etárias e indivíduos com desvios posturais, desde que haja algumas adequações e cuidados (FERREIRA et al., 2008). Junto ao TF utilizamos as periodizações ondulatória e linear, para tentar retirar ou diminuir tais desvios.

Segundo Bompa (2002), a periodização tem como objetivo a melhora do desempenho, pois ela deve se organizar de forma estratégia na montagem do programa, adequando-se as fases e suas variáveis a serem adaptadas. Para Kraemer e 
Hakkinen (2004), a periodização pode ser utilizada em populações como atletas, praticantes de atividade física dentre outros.

Diante desse contexto é assumido neste estudo, em seu sentido mais amplo, descrever os principais desvios posturais caracterizados a princípio, por um desajuste do tônus muscular. Tendo como objetivo verificar se o treinamento de força pode amenizar ou reconduzir a coluna na sua posição anatômica.

\section{MATERIAL E MÉTODO}

\subsection{TIPO DE ESTUDO}

O estudo tem caráter de cunho quantitativo, que segundo (MARCONI; LAKATOS, 2009). A presente pesquisa foi delineada em dois momentos, sendo um bibliográfico, seguindo a metodologia de Teixeira (2008) e o outro de campo.

\subsection{AMOSTRA}

A amostra do presente estudo consistiu em 7 participantes, composta por 4 homens e 3 mulheres com idade média de 23,5 anos ( $D P \pm$ ano), que foram abordados na UFPA, sendo convidado a fazer a avaliação. A amostra foi composta por 2 homens e 1 mulher com escoliose, 1 homem e 2 mulheres com hipercifose torácica e 1 mulher hiperlordose lombar.

Foram incluídos na amostra indivíduos entre 18 e 30 anos e que já tinham praticado TF pelo menos um período de 3 meses no referido ano. Foram excluídos da amostra indivíduos com menos de 3 meses de pratica TF e que não correspondia a faixa etária estipulada.

\subsection{ASPECTOS ÉTICOS}

Esta pesquisa está baseada na resolução 466/12 do Conselho Nacional de Saúde, do Ministério da Saúde do Brasil, que trata sobre pesquisa com seres humanos. A identidade dos participantes foi preservada e os dados coletados foram utilizados 
apenas para o objetivo que a pesquisa se propôs em analisar. Os sujeitos da pesquisa que concordaram em participar da pesquisa, assinaram o Termo de Consentimento Livre e Esclarecido (TCLE) (Apêndice A).

\subsection{INSTRUMENTOS DE COLETA DE DADOS}

Para a coleta dos dados foram utilizados dois instrumentos: Simetrógrafo (Figura 1) aparelho contém linhas horizontais e verticais que possibilitam ao treinador realizar uma avaliação subjetiva do desvio postural (MOLINARI, 2000) e o software Sapo versão 0.69 é um software gratuito de avaliação postural com tutoriais científicos e criação de um banco de dados e está disponibilizado no endereço http://sapo.incubadora.fapesp.br.

Figura 1: Simetrógrafo.

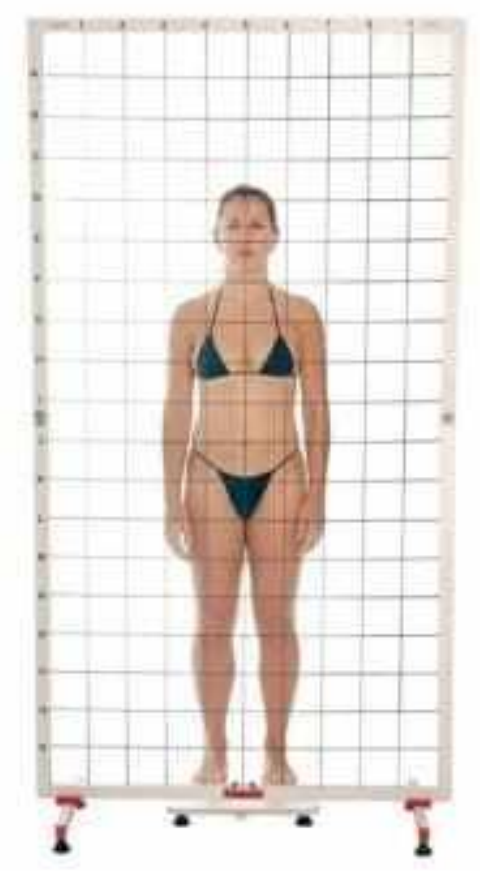

Fonte: Simetrógrafo Portátil - Sanny - HB Fisioterapia. 
A figura 2 apresenta a Tela do Programa SAPO, que consiste em um Software para Avaliação Postural, em desenvolvimento, é um programa de computador gratuito para avaliação postural, com banco de dados e fundamentação científica.

Figura 2: Tela do programa SAPO com quatro imagens abertas:

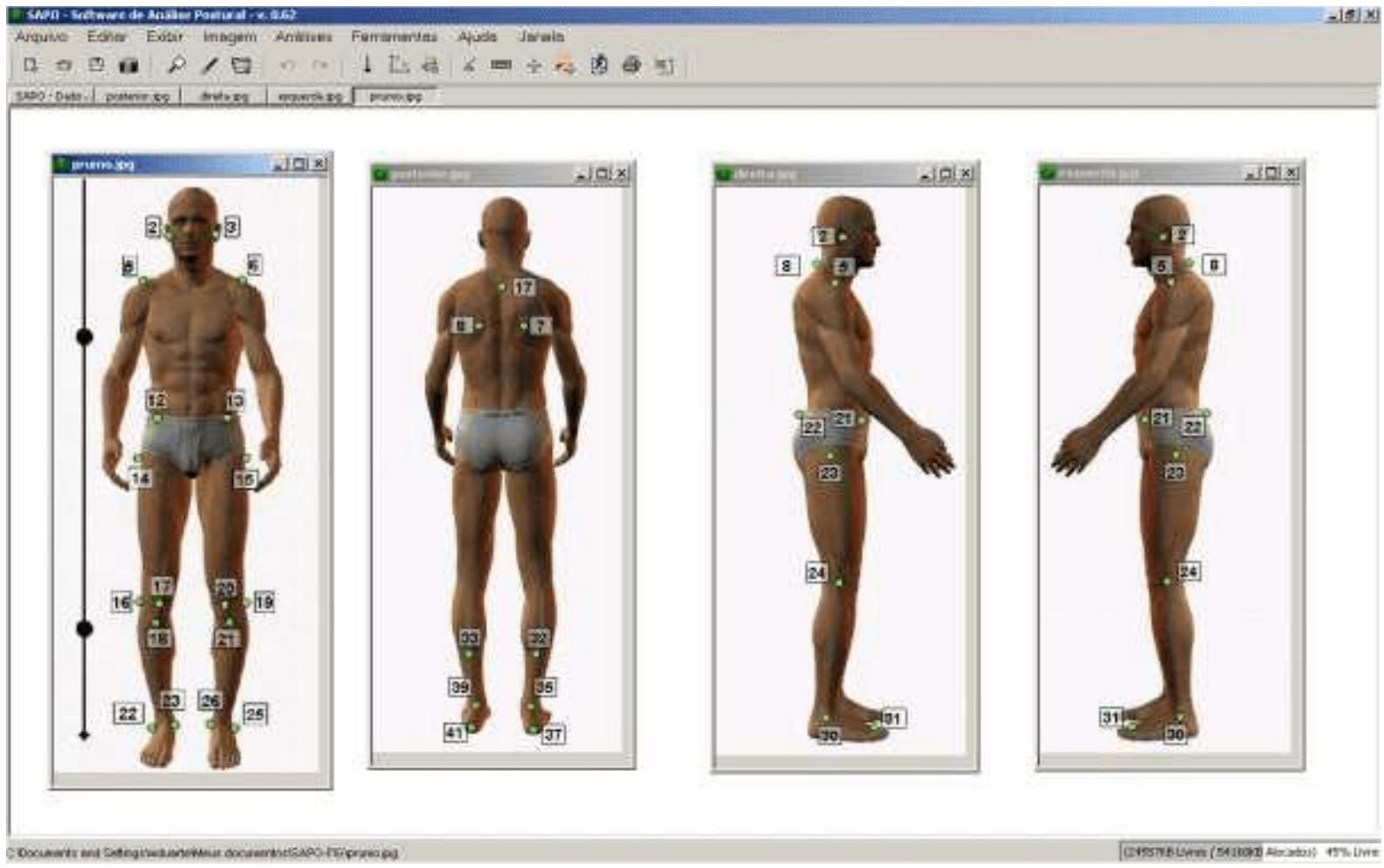

Fonte: http://demotu.org/sapo/

\subsection{PROCEDIMENTOS}

Para obter a amostra dos participantes foi feita uma abordagem com alguns estudantes na UFPA, campus Castanhal, que relataram subjetivamente ter desvio postural. Foi explicado pelo pesquisador, informações sobre riscos, voluntariedade na participação e sigilo com relação aos dados. Feito isso, os participantes assinaram o TCLE, fizeram a avaliação física, processo que ocorreu com duração média de 25 minutos para cada indivíduo.

A seguir, foi solicitado ao sujeito para ficar em traje de praia para serem mensuradas a altura e a massa (peso em $\mathrm{Kg}$ ) do mesmo, antes de iniciar as fotografias para a 
avaliação através do simetrógrafo. Foram usadas as linhas horizontais e verticais do equipamento para guiar a avaliação sobre os alinhamentos corporais do avaliado. Verificou-se a partir daí os possíveis desvios posturais que o indivíduo apresentava. Para isso tivemos alguns principais pontos anatômicos de referência, disponibilizados pelo software utilizado. Tais pontos foram de suma importância na avaliação feita, tais como: a ponta do nariz, o manúbrio e a linha alba, na vista anterior, a sétima vertebra cervical, na vista posterior e o orifício auricular na vista lateral direita e esquerda, que a partir dessa posição podemos observar se há o aumento acentuado da hipercifóse torácica e hiperlordose lombar e na vista anterior pode se observar se o avaliado possuía o desalinhamento do ombro, caracterizando a escoliose. Toda as avaliações foram feitas no Laboratório de Bases Biológicas, Bioquímica, Nutrição e Fisiologia LABIOQNEF, localizado na Universidade Federal do Pará, Campus Castanhal.

Após 2 dias entramos em contato com os avaliados para informá-los do desvio que cada um apresentou e foram convidados para realizar os treinos prescritos, com duração de 2 meses.

Posteriormente realizaram o programa de treinamento de força o qual é definido segundo (FLECK et al., 1997) como a execução de exercícios físicos contra uma determinada resistência exercida pelo próprio corpo. Os exercício prescritos para os

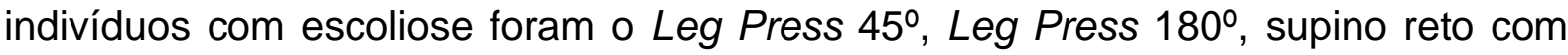
barra, remada sentada, prancha isométrica e o abdominal no banco romano, para os com hipercifóse torácica, voador invertido, supino reto com halteres, remada sentada, voador (peck dack), supino reto com barra e crucifixo invertido e para os hiperlordóticos, o abdominal no banco romano, prancha isométrica, prancha alternada (perdigueiro), flexão de joelho com caneleira, mesa flexora e agachamento na bola suíça.

Todos os exercícios foram realizados 3 dias na semana de forma alternada, durante 8 semanas, cada semana caracteriza um ciclo, sendo a primeiro e a quinta semana o objetivo era hipertrofia, com 3 séries de 10 a 13 repetições, com cadência de 2 segundos na excêntrica e concêntrica e 2 minutos de intervalo, com intensidade subjetiva, sendo os exercícios isométricos com 10 segundo de duração. Na segunda 
e sexta semana o objetivo era Resistência Muscular Localizada (RML), 3 séries de 15 a 20 repetições, cadência de 1segundo na excêntrica e 1 segundo na concêntrica e 1 minuto de descanso e os exercícios isométricos com 30 segundo de duração.

O objetivo dos exercícios da terceira e da sétima semana era a hipertrofia, com 3 séries de 12 a 15 repetições, com cadência de 1 segundos na excêntrica e concêntrica e 2 minutos de intervalo, sendo os exercícios isométricos com 20 segundo de duração. A quarta e oitava semana o objetivo era RML, com 3 séries de 20 a 25 repetições, com cadência de 1 segundos na excêntrica e concêntrica e 1 minutos de intervalo, sendo os exercícios isométricos com 40 segundos de duração cada.

A programação dos exercícios foi baseada no método de treinamento de força utilizando-se de dois tipos de periodização a ondulatória semanal e linear e para ratificar a cadência foi utilizado um aplicativo de celular Metronome Beats, que foi realizado, e acompanhado pelo pesquisador na academia da UFPA, campus Castanhal.

\subsection{ANÁLISE DOS DADOS}

Todos os procedimentos para análise estatística foram realizados por meio dos programas SPSS (Statistical Pakage for Science Social), versão 22.0 para Mac, o SAPO e o Test $T$ pareado. O nível de significância estatística foi estabelecido em $p \leq 0,05$. Inicialmente foi realizada estatística descritiva dos dados obtidos, média e do desvio padrão.

Posteriormente, foi feito uma análise individual baseada no estudo de Ferreira (2005), em que cita que nas medidas obtidas na vista anterior analisadas, quando o sinal for positivo, o lado esquerdo é mais elevado, e quando for negativo, o lado direito é mais elevado e quando for zero, significa que o corpo está alinhado, porém, os resultados têm que compreender entre ( 1 e -1), para caracterizar uma postura adequada. (Figura 3) 
Figura 3: Ângulos avaliados na vista anterior. llustração realizada para este estudo a partir do desenho da figura humana de OKAl (1998).

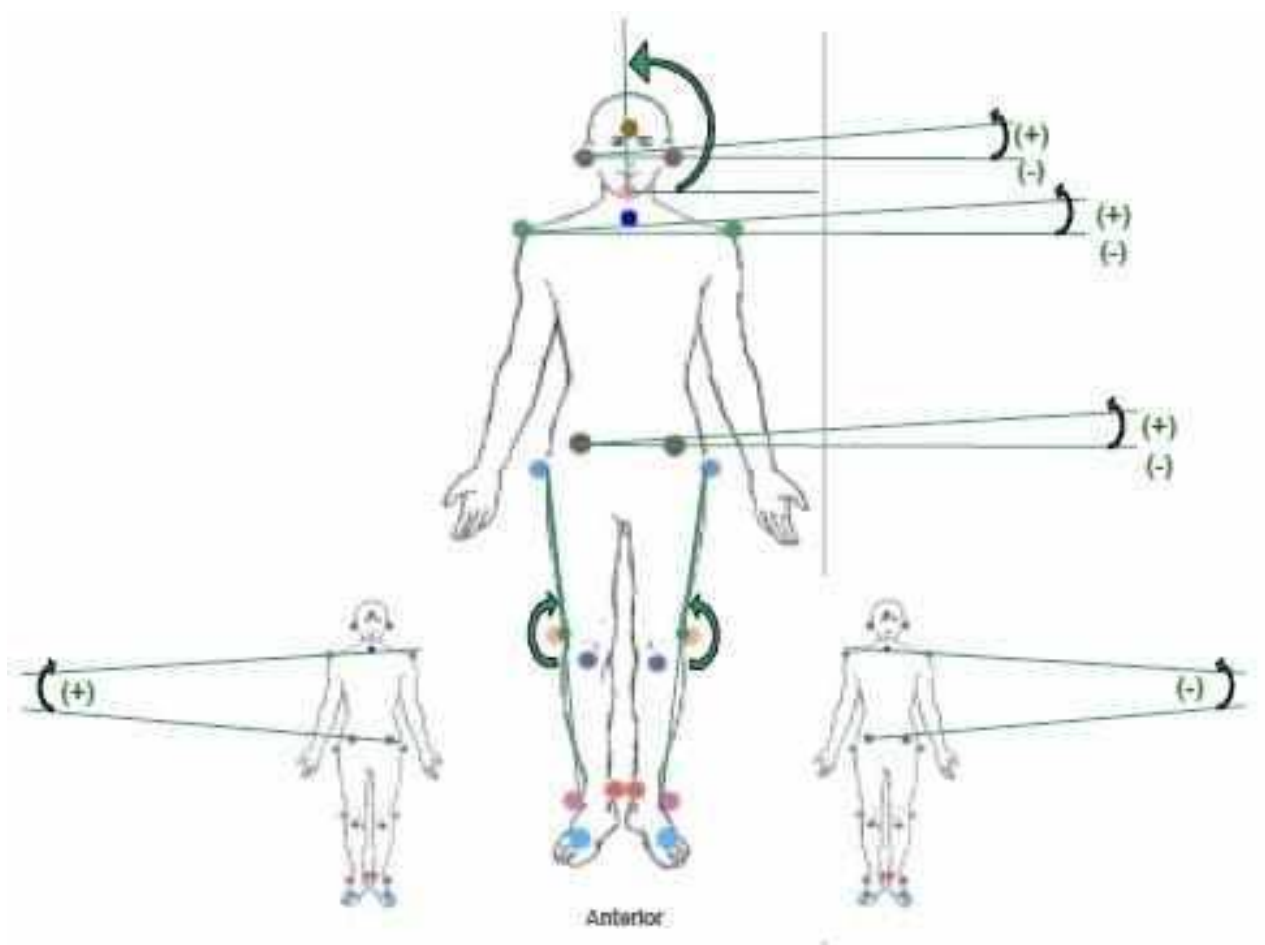

Fonte: ttps://www.bing.com/images/search?q=figura+humana+de+okai+(1998).

\section{RESULTADOS E DISCUSSÃO}

As características descritivas da amostra podem ser observadas na Tabela 1, que traz os valores médios e de desvio-padrão dos pares na vista anterior, posterior, lateral direito e esquerdo, utilizando-se do Test T pareado, identificou-se entre os 29 pares, que o par 2 (vista anterior - VA) e o par 15 (vista lateral direita - VLD) apresentaram resultados mais significativos $(0,007$ e 0,031$)$ respectivamente).

Tabela 1. Teste T de amostras emparelhadas.

\begin{tabular}{|l|l|l|l|l|}
\hline & Média & $\begin{array}{l}\text { Desvio } \\
\text { Padrão }\end{array}$ & Sig. \\
\hline Par 2 & $\begin{array}{l}\text { Pré - Alinhamento horizontal dos acrômios \& Pós } \\
\text { - Alinhamento horizontal dos acrômios - VA }\end{array}$ & 0,7571 & 0,9641 & $0,007^{\star}$ \\
\hline
\end{tabular}


\begin{tabular}{l|lll|l|l|l|l} 
Par 15 & Pré - Alinhamento horizontal da cabeça & 2,6571 & 2,9262 & $0,031^{*}$
\end{tabular} (acrômio) VLD \& PÓS - Alinhamento horizontal da cabeça (acrômio) - VLD

*diferença significativa para os valores pós - treinamento $(p \leq 0,05)$.

Fonte: Dados da pesquisa.

No estudo de Paccini et al. (2007), o qual pesquisou sobre o efeito de exercícios contra-resistência na postura de mulheres, 12 voluntárias entre 18 e 25 anos, sedentárias ou moderadamente ativas, utilizando metodologia semelhante. Observase que o GT registrou melhora em $50 \%$ dos casos no segmento cabeça/pescoço, enquanto para o GC não houve ( $0 \%$ nenhuma mudança, nos acrômios constatou-se melhora em $16,6 \%$ dos casos no GT e em $0 \%$ no GC, os resultados corroboram com a pesquisa.

Quando feito uma subtração entre o pós e o pré treino, analisados individualmente, as características descritivas da amostra, pode ser observadas, na vista anterior (VA), vista posterior (VP), vista lateral direito e esquerdo (VLD e VLE), houve melhora significativa em vários ângulos analisados, porém, destacamos dois indivíduos escolióticos um do sexo masculino e o outro do sexo feminino, que tiveram melhoras em mais ângulos avaliados o indivíduo (DP E 1) e o (DP E 2), com melhoras em 8 e 9 ângulos analisados, respectivamente. Esses resultados podem ter influenciado devidos os dois participantes terem realizado o maior número de sessões durante o período estabelecido para o treinamento. Todos mostrados na (Tabela 2). 
Tabela 2: Análise individual dos ângulos analisados.

\begin{tabular}{|c|c|c|c|c|c|c|c|}
\hline & $\begin{array}{c}\text { DP } \\
\mathrm{E} \\
1^{\star \star}\end{array}$ & $\begin{array}{l}\text { DP } \\
E \\
M \\
2^{*}\end{array}$ & $\begin{array}{c}\text { DP } \\
\text { E } \\
H \\
3^{*}\end{array}$ & $\underset{1^{\star \star}}{\mathrm{DP}} \mathrm{HT}$ & $\begin{array}{c}\text { DP } \\
\text { HT } \\
M \\
2^{\star \star \star}\end{array}$ & $\begin{array}{c}\text { DP } \\
\text { HT } \\
M \\
3^{\star \star \star \star}\end{array}$ & $\begin{array}{c}\mathrm{DP} \\
\mathrm{HL} \\
\mathrm{M} \\
\mathbf{1}^{\star \star \star \star}\end{array}$ \\
\hline $\begin{array}{l}\text { PRÉ- Alinhamento horizontal da } \\
\text { cabeça - VA }\end{array}$ & $-1,80$ & $-3,30$ & 1,40 & 4,00 & $-2,80$ & $-5,60$ & 1,80 \\
\hline $\begin{array}{l}\text { PÓS - Alinhamento horizontal } \\
\text { da cabeça - VA }\end{array}$ & -0 & $-3,20$ & 1,40 & 0,00 & 3,90 & $-3,90$ & $-4,20$ \\
\hline Resultado & 1,80 & $0,10^{*}$ & $0,00^{*}$ & $-4,00$ & 6,70 & 1,70 & $-6,00$ \\
\hline $\begin{array}{l}\text { PRÉ- Alinhamento horizontal } \\
\text { dos acrômios - VA }\end{array}$ & 2,5 & $-0,80$ & 1,70 & 1,50 & $-2,70$ & $-2,50$ & $-0,50$ \\
\hline $\begin{array}{l}\text { PÓS - Alinhamento horizontal } \\
\text { dos acrômios - VA }\end{array}$ & 2,4 & $-3,20$ & 0,00 & 0,70 & $-2,50$ & $-3,00$ & $-0,50$ \\
\hline Resultado & $-0,10^{*}$ & $-2,40$ & $-1,70$ & $-0,80^{*}$ & $0,20^{*}$ & $-0,50^{*}$ & $0,00^{*}$ \\
\hline $\begin{array}{l}\text { PRÉ - Alinhamento horizontal } \\
\text { das espinhas iliacas ântero- } \\
\text { superiores - VA }\end{array}$ & -0 & $-5,00$ & 1,00 & $-1,00$ & 0,00 & 0,00 & 1,80 \\
\hline $\begin{array}{l}\text { PÓS - Alinhamento horizontal } \\
\text { das espinhas ilíacas ântero- } \\
\text { superiores - VA }\end{array}$ & 2,5 & $-5,1$ & $-2,3$ & $-0,7$ & 0,00 & $-3,9$ & 0,80 \\
\hline Resultado & 2,50 & $-0,10^{*}$ & $-3,30$ & $0,30^{*}$ & $0,00^{*}$ & $-3,90$ & $-1,00^{*}$ \\
\hline $\begin{array}{l}\text { PRÉ - Ângulo entre os dois } \\
\text { acrômiose as duas espinhas } \\
\text { iliacas ântero-superiores - VA }\end{array}$ & $-2,5$ & $-4,1$ & $-0,7$ & $-2,4$ & 2,7 & 2,5 & 2,3 \\
\hline $\begin{array}{l}\text { PÓs - Ângulo entre os dois } \\
\text { acrômiose as duas espinhas } \\
\text { iliacas ântero-superiores - VA }\end{array}$ & 0,1 & $-1,9$ & $-2,3$ & $-1,5$ & 2,5 & $-0,8$ & 1,4 \\
\hline Resultado & 2,60 & 2,20 & $-1,60$ & $0,90^{*}$ & $-0,20^{*}$ & $-3,30$ & $-0,90^{*}$ \\
\hline $\begin{array}{l}\text { PRÉ - Ângulo frontal do membro } \\
\text { direito - VA }\end{array}$ & 5,5 & $-1,3$ & 2,1 & $-5,2$ & $-0,8$ & $-4,5$ & $-4,8$ \\
\hline $\begin{array}{l}\text { PÓS - Ângulo frontal do } \\
\text { membro direito - VA }\end{array}$ & 6,3 & $-2,2$ & 3,3 & $-0,2$ & -0 & $-6,1$ & 3,8 \\
\hline
\end{tabular}




\begin{tabular}{|c|c|c|c|c|c|c|c|}
\hline Resultado & $0,80^{*}$ & $-0,90^{*}$ & 1,20 & 5,00 & $0,80^{*}$ & $-1,60$ & 8,60 \\
\hline $\begin{array}{l}\text { PRÉ - Ângulo frontal do membro } \\
\text { esquerdo - VA }\end{array}$ & 3,9 & 1,1 & 3,7 & $-2,8$ & $-5,5$ & $-1,8$ & $-3,4$ \\
\hline $\begin{array}{l}\text { PÓS - Ângulo frontal do } \\
\text { membro esquerdo - VA }\end{array}$ & 3,8 & -1 & 4,1 & 3,1 & $-2,7$ & $-1,9$ & $-1,1$ \\
\hline Resultado & $-0,10^{*}$ & $-2,10$ & $0,40^{*}$ & 5,90 & 2,80 & $-0,10^{*}$ & 2,30 \\
\hline $\begin{array}{l}\text { PRÉ - Diferença no } \\
\text { comprimento dos membros } \\
\text { inferiores (D-E) - VA }\end{array}$ & 0,1 & -0 & $-0,5$ & $-0,2$ & -0 & 0 & $-0,7$ \\
\hline $\begin{array}{l}\text { PÓS - Diferença no } \\
\text { comprimento dos membros } \\
\text { inferiores (D-E) - VA }\end{array}$ & $-0,6$ & 0,9 & 0,4 & $-0,3$ & $-0,7$ & 1,2 & -1 \\
\hline Resultado & $-0,70^{*}$ & $0,90^{*}$ & $0,90^{*}$ & $-0,10^{*}$ & $-0,70^{*}$ & 1,20 & $-0,30^{*}$ \\
\hline $\begin{array}{l}\text { PRÉ - Ângulo perna/retropé } \\
\text { esquerdo - VP }\end{array}$ & 16,9 & 7,9 & 13 & 14,2 & 5,8 & 18,3 & 15,3 \\
\hline $\begin{array}{l}\text { PÓS - Ângulo perna/retropé } \\
\text { esquerdo - VP }\end{array}$ & 7,1 & 7,8 & 6,3 & 10,4 & 11,7 & 4,6 & 6,8 \\
\hline Resultado & $-9,80$ & $-0,10^{*}$ & $-6,70$ & $-3,80$ & 5,90 & $-13,70$ & $-8,50$ \\
\hline $\begin{array}{l}\text { PRÉ - Alinhamento vertical do } \\
\text { tronco - VLD }\end{array}$ & 0,5 & -0 & 3,3 & 1 & 0,5 & 1,7 & $-1,5$ \\
\hline $\begin{array}{l}\text { PÓS - Alinhamento vertical do } \\
\text { tronco - VLD }\end{array}$ & 1,1 & 1,8 & 0,9 & 0,3 & -0 & 0,4 & 0,9 \\
\hline Resultado & $0,60^{*}$ & 1,80 & $-2,40$ & $-0,70^{*}$ & $-0,50^{*}$ & $-1,30$ & 2,40 \\
\hline $\begin{array}{l}\text { PRÉ - ângulo do quadril (tronco } \\
\text { e coxa) - VLD }\end{array}$ & $-3,6$ & $-8,9$ & 0,3 & $-2,7$ & $-5,2$ & $-2,9$ & $-5,9$ \\
\hline $\begin{array}{l}\text { PÓs - ângulo do quadril (tronco } \\
\text { e coxa) - VLD }\end{array}$ & $-3,3$ & $-3,7$ & $-0,9$ & $-6,1$ & $-6,3$ & $-5,1$ & $-4,1$ \\
\hline Resultado & $0,30^{*}$ & 5,20 & $-1,20$ & $-3,40$ & $-1,10$ & $-2,20$ & 1,80 \\
\hline $\begin{array}{l}\text { PRÉ - Alinhamento vertical do } \\
\text { corpo - VLD }\end{array}$ & 3,8 & 2,4 & 4,4 & 2,5 & 2 & 2,9 & 2,4 \\
\hline
\end{tabular}




\begin{tabular}{|c|c|c|c|c|c|c|c|}
\hline $\begin{array}{l}\text { PÓS - Alinhamento vertical do } \\
\text { corpo - VLD }\end{array}$ & 2,7 & 2,8 & 3 & 2,7 & 2,2 & 2,4 & 3 \\
\hline Resultado & $-1,10$ & $0,40^{*}$ & $-1,40$ & $0,20^{*}$ & $0,20^{*}$ & $-0,50^{*}$ & $0,60^{*}$ \\
\hline $\begin{array}{l}\text { PRÉ - Alinhamento horizontal da } \\
\text { pélvis - VLD }\end{array}$ & 2,2 & $-7,4$ & $-19,4$ & $-17,4$ & $-7,4$ & -13 & $-14,8$ \\
\hline $\begin{array}{l}\text { PÓS - Alinhamento horizontal } \\
\text { da pélvis - VLD }\end{array}$ & $-1,2$ & $-17,2$ & $-19,8$ & $-7,2$ & -16 & $-12,6$ & -10.3 \\
\hline Resultado & $-3,40$ & $-9,80$ & $-0,40^{*}$ & 10,20 & $-8,60$ & $0,40^{*}$ & 4,50 \\
\hline PRÉ - Ângulo do joelho - VLD & 4 & $-6,2$ & 4 & $-0,1$ & $-4,5$ & -1.1 & 0,8 \\
\hline PÓs - Ângulo do joelho - VLD & $-0,6$ & $-3,6$ & 5,3 & $-4,1$ & $-3,1$ & $-1,7$ & -0 \\
\hline Resultado & $-4,60$ & 2,60 & 1,30 & $-4,00$ & 1,40 & $-0,60^{*}$ & $-0,80^{*}$ \\
\hline $\begin{array}{l}\text { PRÉ - Ângulo do tornozelo - } \\
\text { VLD }\end{array}$ & 81,8 & 87,3 & 83 & 86,4 & 88,7 & 86,5 & 84,7 \\
\hline $\begin{array}{l}\text { PÓS - Ângulo do tornozelo - } \\
\text { VLD }\end{array}$ & 86,2 & 88,1 & 82,9 & 87,6 & 86,8 & 86,2 & 85 \\
\hline Resultado & 4,40 & $0,80^{*}$ & $-0,10^{*}$ & 1,20 & $-1,90$ & $-0,30^{*}$ & $0,30^{*}$ \\
\hline $\begin{array}{l}\text { PRÉ - Alinhamento vertical do } \\
\text { tronco - VLE }\end{array}$ & 0 & -4 & 4,2 & 2,2 & $-2,8$ & $-0,7$ & $-2,5$ \\
\hline $\begin{array}{l}\text { PÓs - Alinhamento vertical do } \\
\text { tronco - VLE }\end{array}$ & $-0,7$ & $-2,9$ & $-0,7$ & $-3,2$ & $-6,5$ & $-1,5$ & $-1,1$ \\
\hline Resultado & $-0,70^{*}$ & 1,10 & $-4,90$ & $-5,40$ & $-3,70$ & $-0,80^{*}$ & 1,40 \\
\hline $\begin{array}{l}\text { PRÉ - Ângulo do quadril (tronco } \\
\text { e coxa) - VLE }\end{array}$ & 3 & $-6,7$ & 2,7 & 2,2 & $-9,9$ & $-7,3$ & $-4,1$ \\
\hline $\begin{array}{l}\text { PÓS - Ângulo do quadril (tronco } \\
\text { e coxa) - VLE }\end{array}$ & $-0,7$ & $-6,1$ & $-5,4$ & $-4,5$ & -14 & $-3,3$ & 0,3 \\
\hline Resultado & $-3,70$ & $0,60^{*}$ & $-8,10$ & $-6,70$ & $-4,10$ & 4,00 & 4,40 \\
\hline $\begin{array}{l}\text { PRÉ - Alinhamento vertical do } \\
\text { corpo - VLE }\end{array}$ & 1 & $-0,8$ & 3,8 & 1,6 & 0,4 & 2,2 & $-0,4$ \\
\hline $\begin{array}{l}\text { PÓS - Alinhamento vertical do } \\
\text { corpo - VLE }\end{array}$ & 0,7 & $-0,2$ & 2,5 & 0,7 & $-2,3$ & 0,2 & 0,7 \\
\hline Resultado & $-0,30^{*}$ & $0,60^{*}$ & $-1,30$ & $-0,90^{*}$ & $-2,70$ & $-2,00$ & 1,10 \\
\hline
\end{tabular}

\begin{tabular}{|l|c|c|c|c|c|c|c|}
\hline PRÉ - Ângulo do tornozelo - VLE & 84,4 & 87,1 & 85,3 & 87,8 & 90,5 & 86,8 & 88,8 \\
\hline $\begin{array}{l}\text { PÓS - Ângulo do tornozelo- } \\
\text { VLE }\end{array}$ & 86,2 & 90 & 84,5 & 84,1 & 91,4 & 88,6 & 85 \\
\hline Resultados & 2,10 & 2,90 & $-0,80^{*}$ & $-3,70$ & 1,40 & 1,80 & $-3,80$ \\
\hline
\end{tabular}


DP: Desvio postural / E: Escoliose / HT: Hipercífose torácica / HL: Hiperlordose lombar / H: Homem / M: Mulher / VA: Vista anterior / VP: Vista posterior / VLD/E: Vista lateral

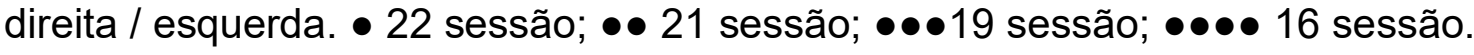

Fonte: Dados da pesquisa.

Os resultados mostrados acima são corroborados com o estudo de caso citado por Marques (1996), o qual utilizou a Reeducação Postural Global (RPG) para aplicar em um indivíduo com escoliose, diagnosticada através de RX, utilizou 16 sessões com duração de uma hora cada, após as sessões, reavaliou através do $R X$, e verificou uma diferença significante no escoliótico, especificamente no membro inferior direito. Divergindo com a pesquisa Knoplich (2016), cita que para fortalecer os músculos retoabdominais, devem-se fazer somente os exercícios isométricos que, na realidade, se resumem em um único.

Segundo Knoplich (2016), a musculatura das costas envolvidas em alguns exercícios: o voador, a remada sentada e outros, é uma poderosa musculatura que não se encontram em nenhuma circunstância fraca, caso isso ocorra o ser humana não teria condições de manter a posição ereta, ou seja, esses músculos não serão recuperados com exercício físico com o objetivo de fortalecimento e sim de relaxamento neuromuscular e recuperação da postura humana.

\section{CONCLUSÃO}

O estudo mostra por meio dos resultados, que o TF não foi suficiente para retirar ou amenizar os desvios posturais nos indivíduos acometidos. Pois, mostrou significância em apenas dois pares analisados e alguns ângulos anatômicos. Pode ser que um treinamento mais voltado para as capacidades físicas funcionais, tais como: força, equilíbrio, resistência, flexibilidade, fosse mais eficiente para retirá-los de sua atual posição anatômica alterada.

Identificaram-se ajustes em alguns ângulos analisados, porém, não foi suficiente para reconduzir a coluna para uma postura adequada. Como observados as melhoras em 
alguns escolióticos. Compreendemos que a pesquisa demonstrou que somente o treinamento de força não surtiu efeito para amenizar ou reconduzir a coluna na sua posição anatômica normal.

Portanto, se faz necessário aplicar outros métodos de treinamentos que possam surtir efeitos positivos para esses pacientes. Essa pesquisa poderá colaborar em futuras discussões em torno dessa temática e que possam beneficiar as pessoas portadoras de desvios posturais anatômicos.

\section{REFERÊNCIAS}

BLACK, A. Escola Postural: uma alternativa para a saúde da coluna vertebral. Porto Alegre: Rígel, 1993.

BOMPA, T. O. Periodização: teoria e metodologia do treinamento. 4 ed. São Paulo: Phorte Editora, 2002.

FERREIRA, E. A. G. Postura e controle postural: desenvolvimento e aplicação de método quantitativo de avaliação postural. 2005. $114 \mathrm{f}$ (Doutorado em Medicina) Universidade de São Paulo, 2005.

FERREIRA, A. C. D. E. et al. Musculação: aspectos fisiológicos, neurais, metodológicos e nutricionais. XI Encontro de Iniciação a Docência. UFPB-PRG, 2008.

FLECK, S.; FIGUEIRA J.; AYLTON J. Riscos e benefícios do treinamento de força em crianças: novas tendências. Revista Brasileira de Atividade Física e Saúde, São Paulo, v. 2, n. 1, p. 69-75, 1997.

HAMILL, J.; KNUTZEN, K. M. Bases biomecânicas do movimento humano. São Paulo: Malone, 1999.

HEBERT, S. et al. Ortopedia e traumatologia: princípios e prática. $4^{\underline{a}}$ ed. Porto Alegre: Artmed Editora, 2009. 
KAPANDJI, I. A. Fisiologia Articular Tronco e Coluna Vertebral, ed Paramericana, 2008.

KNOPLICH, J. Viva bem com a coluna que você tem: dores na costa: tratamento e prevenção. 32ª ed. Barueri: Manole, 2016.

KRAEMER, W. J.; HAKKINEN, K. Treinamento de força para o esporte. Porto Alegre: Artmed, 2004.

MARCONI, M. A.; LAKATOS, E. M. Fundamentos de Metodologia Científica. $6^{\underline{a}}$ ed. São Paulo: Editora Atlas S. A., 2009.

MARQUES, A. P. Escoliose tratada com reeducação postural global. Rev. Fisioter. Univ. São Paulo, São Paulo, v. 3, n. 1/2, p. 65-68, 1996.

MOLINARI, B. et al. Avaliação médica e física: para atletas e praticantes de atividades físicas. Ed. Roca, São Paulo, 2000.

OKAI, L. A. Avaliação funcional de um laboratório de marcha. São Paulo; 1998.

PACCINI, M. K. et al. Efeito de exercícios contra-resistência na postura de mulheres. Rev. da Educação Física/UEM, Maringá, v. 18, n. 2, p. 169-175, 2007.

RESENDE, J. A.; SANCHES, D. Avaliação dos desvios posturais em crianças com idade escolar de 11 a 16 nos. Revista da Educação Física da UEM, Maringá, v.3, n.1, p.21-16, 1992.

TEIXEIRA, E. As três metodologias: academia da ciência e da pesquisa Petrópolis: Vozes, 2005.

VERDERI, E. Programa de educação postural. 2. Ed. São Paulo: Phorte, 2008.

ZATSIORSKY, V. M.; KRAEMER, W. J. Ciência e Prática do Treinamento de Força. 2. Ed. São Paulo: Phorte, 2008. 
http://www.bing.com/images/search?q=desvios+posturais\&view=detailv2\&\&id=95D1 D1F53A0FF37F02AD9DC579ECB8226706688E\&selectedlndex=99\&ccid=80\%2fs5 Nax\&simid=608033315580281233\&thid=OIP.Mf28fece4d6b17c431 1acbfd44aa4aa6 co0\&ajaxhist $=0$

https://www.google.com.br/search?q=simetrografo\&espv=2\&biw=1366\&bih=667\&sou $r c e=I n m s \& t b m=i s c h \& s a=X \& v e d=0 a h U K E w j C 28 v u 18 X M A h W I h 5 A K H R k 7 D 6 s Q \_A U I B$ ygC\#imgrc=sEFo0tr3fDN_VM\%3Ahttp://sapo.incubadora.fapesp.br

Enviado: Dezembro, 2019.

Aprovado: Dezembro, 2019. 